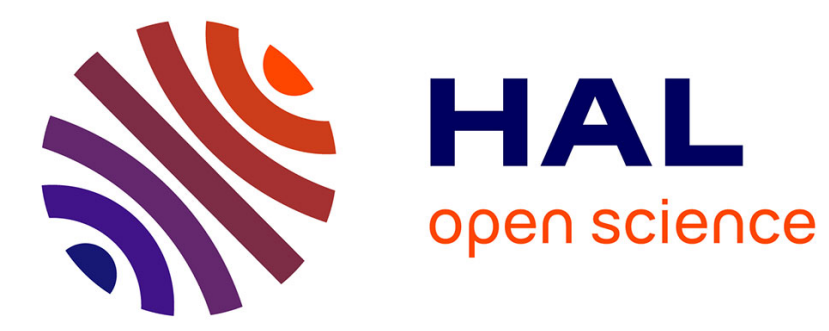

\title{
Syndromic neurodevelopmental disorder associated with de novo variants in DDX23
}

\author{
William Burns, Lynne M Bird, Delphine Heron, Boris Keren, Divya \\ Ramachandra, Isabelle Thiffault, Florencia del Viso, Shivarajan Amudhavalli, \\ Kendra Engleman, Ilaria Parenti, et al.
}

\section{To cite this version:}

William Burns, Lynne M Bird, Delphine Heron, Boris Keren, Divya Ramachandra, et al.. Syndromic neurodevelopmental disorder associated with de novo variants in DDX23. American Journal of Medical Genetics Part A, 2021, 10.1002/ajmg.a.62359 . hal-03251630

\section{HAL Id: hal-03251630 \\ https://hal.sorbonne-universite.fr/hal-03251630}

Submitted on 7 Jun 2021

HAL is a multi-disciplinary open access archive for the deposit and dissemination of scientific research documents, whether they are published or not. The documents may come from teaching and research institutions in France or abroad, or from public or private research centers.
L'archive ouverte pluridisciplinaire HAL, est destinée au dépôt et à la diffusion de documents scientifiques de niveau recherche, publiés ou non, émanant des établissements d'enseignement et de recherche français ou étrangers, des laboratoires publics ou privés. 


\section{appliedbiosystems}

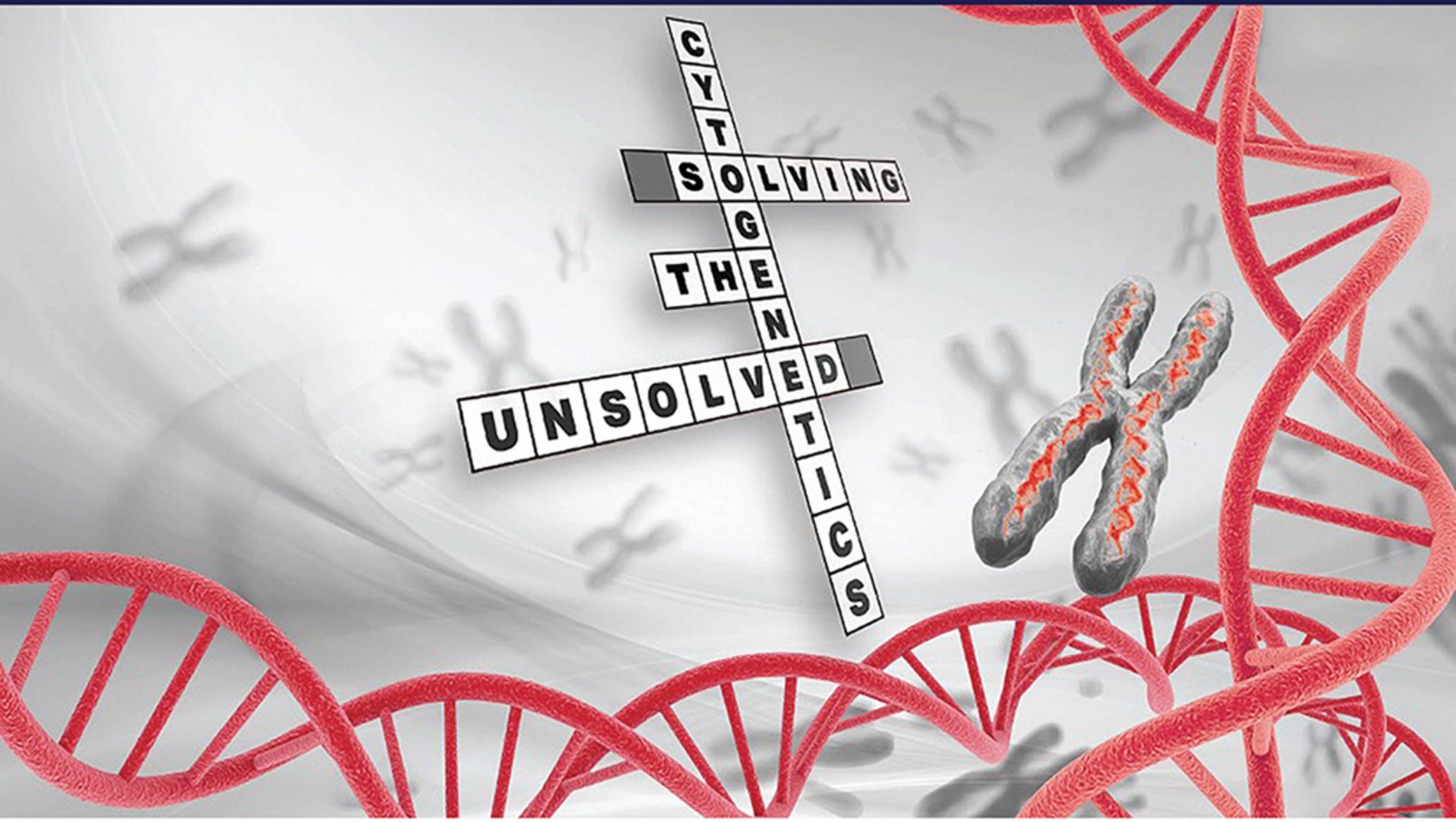

\section{When does CMA make a difference in the era of NGS?}

Watch these brief case study videos featuring chromosomal microarray (CMA) to learn more from industry experts

In this new video series, discover how hybrid single-nucleotide polymorphism (SNP) arrays make a difference in real-world studies of complex genetic cases. In the first episode, Dr. Stuart Schwartz discusses how the use of high-density hybrid SNP arrays in identifying uniparental disomy (UPD) increased the success of discovering rare diseases.

Video highlights:

- Review of multiple complex case studies

- Importance and complexities of underlying mechanisms

- Detection techniques and management guidelines

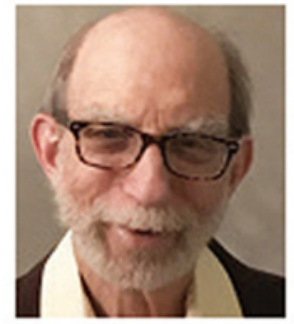

Dr. Stuart Schwartz, PhD, FACMG, Associate VP and Senior Director of Cytogenetics, Laboratory Corporation of America at the Center for Molecular Biology and Pathology (CMBP) 


\title{
Syndromic neurodevelopmental disorder associated with de novo variants in DDX23
}

\author{
William Burns $^{1}$ ( ) | Lynne M. Bird ${ }^{2,3}$ | Delphine Heron ${ }^{4}$ | Boris Keren ${ }^{4}$ | \\ Divya Ramachandra $^{5}$ | Isabelle Thiffault ${ }^{6,7}$ — | Florencia Del Viso ${ }^{6}$ | \\ Shivarajan Amudhavalli $^{8}$ | Kendra Engleman $^{8}$ | |laria Parenti $^{9}$ | Frank J. Kaiser ${ }^{9}$ | \\ Jolanta Wierzba $^{10}$ | Korbinian M. Riedhammer ${ }^{11,12}$ () | Susanne Liptay ${ }^{13}$ | \\ Neda Zadeh ${ }^{14,15}$ | Joseph Porrmann ${ }^{16}$ | Andrea Fischer ${ }^{16}$ | Sophie Gößwein ${ }^{16}$ | \\ Heather M. McLaughlin ${ }^{17}$ | Aida Telegrafi ${ }^{18}$ | Katherine G. Langley ${ }^{18}$ | \\ Richard Steet $^{1}$ | Raymond J. Louie ${ }^{1}$ (c) | Michael J. Lyons ${ }^{1}$ \\ ${ }^{1}$ Greenwood Genetic Center, Greenwood, South Carolina \\ ${ }^{2}$ San Diego - Department of Pediatrics, University of California, San Diego, California \\ ${ }^{3}$ Division of Genetics/Dysmorphology, Rady Children's Hospital San Diego, San Diego, California \\ ${ }^{4}$ Département de Génétique, Pitié-Salpêtrière Hospital, APHP.Sorbonne Université, Paris, France \\ ${ }^{5}$ Division of Genetics, Advocate Hope Children's Hospital, Oak Lawn, Illinois \\ ${ }^{6}$ Center for Pediatric Genomic Medicine, Children's Mercy Hospital, Kansas City, Missouri \\ ${ }^{7}$ University of Missouri-Kansas City School of Medicine, Kansas City, Missouri \\ ${ }^{8}$ Department of Pediatics, Children's Mercy Hospital, Kansas City, Missouri \\ ${ }^{9}$ Institut für Humangenetik, Universitätsklinikum Essen, Universität Duisburg-Essen, Essen, Germany \\ ${ }^{10}$ Department of Pediatric and Internal Medicine Nursing, Medical University of Gdańsk, Poland \\ ${ }^{11}$ Institute of Human Genetics, Klinikum rechts der Isar, School of Medicine, Technical University of Munich, Munich, Germany \\ ${ }^{12}$ Department of Nephrology, Klinikum rechts der Isar, School of Medicine, Technical University of Munich, Munich, Germany \\ ${ }^{13}$ Department of Pediatrics, Kinderklinik München Schwabing, School of Medicine, Technical University of Munich, Munich, Germany \\ ${ }^{14}$ Genetics Center, Orange, California \\ ${ }^{15}$ Division of Medical Genetics, CHOC Children's Hospital, Orange, California \\ ${ }^{16}$ Faculty of Medicine Carl Gustav Carus, TU Dresden, Fetscherstr. 74, Institute for Clinical Genetics, Dresden, Germany \\ ${ }^{17}$ Invitae Corporation, San Francisco, California \\ ${ }^{18}$ GeneDx, Gaithersburg, Maryland
}

\section{Correspondence}

Michael J. Lyons, Greenwood Genetic Center, 3520 West Montague Avenue, Suite 104, North Charleston, SC 29418, USA.

Email: mlyons@ggc.org

\section{Abstract}

The DEAD/DEAH box RNA helicases are a superfamily of proteins involved in the processing and transportation of RNA within the cell. A growing literature supports this family of proteins as contributing to various types of human disorders from neurodevelopmental disorders to syndromes with multiple congenital anomalies. This article presents a cohort of nine unrelated individuals with de novo missense alterations in DDX23 (Dead-Box Helicase 23). The gene is ubiquitously expressed and functions in RNA splicing, maintenance of genome stability, and the sensing of double-stranded RNA. Our cohort of patients, gathered through GeneMatcher, exhibited features including tone abnormalities, global developmental delay, facial 
dysmorphism, autism spectrum disorder, and seizures. Additionally, there were a variety of other findings in the skeletal, renal, ocular, and cardiac systems. The missense alterations all occurred within a highly conserved RecA-like domain of the protein, and are located within or proximal to the DEAD box sequence. The individuals presented in this article provide evidence of a syndrome related to alterations in DDX23 characterized predominantly by atypical neurodevelopment.

\section{KEYWORDS}

DDX23, neurodevelopment, RNA helicase

\section{1 | INTRODUCTION}

In recent literature, DEAD/DEAH box (DDX/DHX) RNA helicases have been increasingly associated with distinct human disease phenotypes. The DDX23 gene (OMIM* 612172; GenelD: 1519246410), located at $12 q 13.12$, is ubiquitously expressed and encodes a DEAD box RNA helicase (named DDX23 or Prp28) with the primary role of assisting in the creation of the mature spliceosome, but with secondary functions related to genomic stability maintenance through R-loop suppression and a role in viral immunity as a dsRNA sensor (Möhlmann et al., 2014; Ruan et al., 2019; Sridhara et al., 2017; Teigelkamp et al., 1997). Multiple cancers have been associated with increased presence of R-loops due to reduced function of DDX23 protein, further stressing its importance in genomic stability (Chae et al., 2015). Interestingly, upregulation of DDX23 has also been associated with increased risk of malignancy and metastasis for unknown reasons (Mao et al., 2017; Yin et al., 2015). With the exception of somatic loss of function in cancers, no phenotype has previously been reported in relation to DDX23 variants. In this study, we present a cohort of nine patients with constitutional variants in DDX23 and propose they are associated with an autosomal dominant neurodevelopmental syndrome.

\section{2 | MATERIALS AND METHODS}

This cohort of patients was collected through GeneMatcher (https:// genematcher.org/ Sobreira et al., 2015). Individuals with variants in the DDX23 gene were identified through exome sequencing and genome sequencing. Phenotypic information was obtained through review of patient medical records. Informed consent was obtained and approved through appropriate institutional internal review committees.

Standard laboratory procedures were used for exome analyses and were performed in diagnostic laboratories. The whole genome sequencing was performed in a research laboratory. In general, comparable procedures were implemented for DNA isolation, sequencing, bioinformatics processing, and variant interpretation. The reference sequence of the DDX23 transcript used in this study is NM_004818.2 (Figure 1).

\section{3 | RESULTS}

\subsection{Patient 1}

Patient 1 is a now 2-year and 10-month old female born full term to a 27-year-old G3P1 mother. She was born via spontaneous vaginal delivery without complications. Her birth weight was $3.1 \mathrm{~kg}$ (Z-score $=-0.29)$ with a length of $50.8 \mathrm{~cm}(Z$-score $=0.89)$ and head circumference of $34.5 \mathrm{~cm}$ (Z-score $=0.52$ ). Following delivery, there were no complications and the patient was discharged home within 48 hours of birth. Family history is unremarkable.

Hypotonia and developmental delay were first noted at 5 months of age by her daycare attendants. She was initially seen in genetics clinic at 9 months of age for developmental delays and hypotonia,

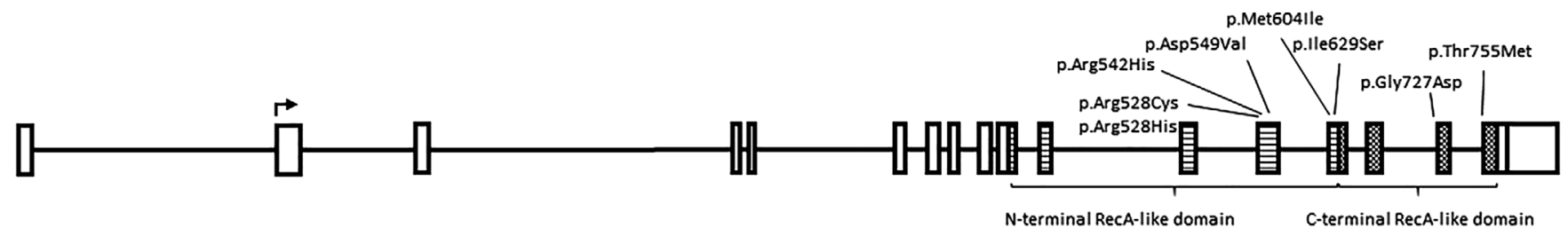

FIGURE 1 Schematic of the DDX23 gene. The DDX23 gene (NM_004818.2) consists of 17 exons, with the start codon (arrow) located in exon 2. Exons 10-17 encode for the N-terminal RecA-like domain (striped pattern) and C-terminal RecA-like domain (checkered pattern). The locations of all the DDX23 variants described in this study are annotated above the schematic. Annotation of functional domains are based on the study by Möhlmann et al. (2014) 
which was improving. Physical exam was significant for generalized hypotonia, full cheeks, mild epicanthal folds, short palpebral fissures, and low nasal bridge. Prior to the genetic evaluation, she had been seen by a pediatric neurologist who sent biochemical testing, including acylcarnitine profile, free/total carnitine, plasma amino acids, creatine kinase, and urine organic acids. This testing was normal.

Developmental progress continued steadily with no periods of regression. At age 2, she was attempting to kneel and sit up. She used Supra-Malleolar Orthosis (SMO) due to excessive pronation. Her speech was significantly delayed with no spoken words and consistent use of approximately six hand signs. Her most recent evaluation noted height of $76.3 \mathrm{~cm}$ (Z-score $=-2.84$ ), weight of $9.8 \mathrm{~kg}$ (Z-score $=-1.11)$, and head circumference of $48.2 \mathrm{~cm}(Z$-score $=0.67)$.

\subsection{Patient 2}

Patient 2 was a 7-year-old male at the time of analysis born via Csection complicated by respiratory distress. Pregnancy was uncomplicated. Prenatal ultrasounds revealed an echogenic focus in the left cardiac ventricle. Following delivery, he was diagnosed with pulmonary hypertension requiring a prolonged NICU admission. His family history is significant for a maternal aunt who did not walk until the age of 4 years and now requires a wheelchair for mobility.

His initial genetic evaluation occurred as a toddler for a history of global developmental delay. Prior to the genetic evaluation, he was seen by neurology and had a brain MRI indicating possible decreased white matter and corpus callosum abnormalities. He developed seizures at the age of 5 , which led to loss of language. He remains nonverbal at the age of 7. Motor milestones were delayed. He did not walk until the age of 2 and was unable to grasp objects until 1 year of age. Other medical concerns include severe myopia (estimated -10 diopters). His dysmorphology exam is unremarkable except for protrusion of upper lip (Figure 2a-c).

\section{3 $\quad$ Patient 3}

Patient 3 is an 8 -year-old male with an unremarkable prenatal and perinatal history. He initially presented with global developmental delay and cryptorchidism. Growth parameters at his most recent visit were a height of $115 \mathrm{~cm}$ (Z-score $=-2.30)$, weight of $27 \mathrm{~kg}$ $(Z$-score $=0.32$ ), and a head circumference of $51 \mathrm{~cm}$ (Z-score $=-1.07)$.

At the age of 8 , he is nonverbal. His motor milestones were delayed. In addition to his delays, he was noted to have stereotypies on evaluation with no diagnosis of autism spectrum disorder. On exam, he was noted to have generalized hypotonia, bilateral ptosis, posteriorly rotated ears, and a tendency to hold his mouth open.

\subsection{Patient 4}

Patient 4 was born at 39 weeks via spontaneous vaginal delivery following an uncomplicated pregnancy. She required resuscitation following delivery due to a reported umbilical cord issue. Congenital anomalies noted in the neonatal period included an atrial septal defect and ventricular septal defect.

Initial genetics evaluation occurred at the age of 4 months for history of failure to thrive and dysphagia secondary to laryngomalacia and hypotonia. Brain MRI revealed gray matter heterotopias alongside portions of the right and left lateral ventricles and thinning of the corpus callosum, but was otherwise unremarkable. On initial exam, exact measurements were unavailable, but clinical assessment noted short stature and a small appearance of the head (Figure 2d). The patient was also diagnosed with Brown's sheath syndrome of the eye.

\subsection{Patient 5}

Patient 5 was born at term following an uncomplicated pregnancy and delivery. She was noted to have atypical facial features that were felt to be consistent with Cornelia de Lange syndrome including hypertrichosis, bushy eyebrows with synophrys, wide nostrils, long plain philtrum, thin lips, and low set ears (Figure 2e).

She was seen by genetics for her history of atypical features and global developmental delays. She has significant speech delay exacerbated by hearing loss. She was also noted to have features consistent with autism spectrum disorder. At the age of 9 , her growth parameters included height of $124 \mathrm{~cm}$ (Z-score $=-1.48$ ), weight of $33.5 \mathrm{~kg}$ (Z-score $=0.73$ ), and head circumference of $49 \mathrm{~cm}$ (Z-score $=-2.07$ ). In addition to the physical exam features noted above, other dysmorphic features identified during the neonatal period included radioulnar synostosis, shortened fifth fingers with camptodactyly bilaterally, and gaps between the first and second toes. Additionally, after birth, she was noted to have mild pulmonary stenosis, which resolved on subsequent echocardiograms.

\section{6 $\quad$ Patient 6}

Patient 6 was born at term following an unremarkable pregnancy and delivery. Following delivery, she was noted to have a cleft of the soft palate requiring surgical repair. She was also diagnosed with mild pectus excavatum and proximal radioulnar synostosis in the right arm. In addition to these congenital anomalies, she was diagnosed with diffuse hypotonia and significant oral dysphagia.

Initial genetics evaluation was at 4 years of age. Her referral was made due to concerns for global developmental delays. At the time of her evaluation, she was walking only with a gait trainer, was nonverbal with limited sign language, and had significant fine motor delays. She had a history of seizures with a brain MRI identifying heterotopic gray matter and corpus callosum dysplasia. She was followed by ophthalmology for cortical vision impairment with myopia and astigmatism. Her growth parameter Z-scores were height -2.30 , weight -2.29 , and head circumference -1.6 . She had bitemporal narrowing, bulbous nasal tip, broad philtrum, full lips, downturned corners of the mouth, bilateral epicanthal folds, and bluish sclerae. Bilateral coxa valga was noted on exam. 


\section{7 $\quad$ Patient 7}

Pregnancy was complicated by intrauterine growth restriction (IUGR) identified by ultrasound. She was born via $\mathrm{C}$-section at 33 weeks and 5 days. Birth weight was $<1$ st percentile for age. She required admission to the NICU for cardiopulmonary support and due to her severe growth restriction. Echocardiogram indicated the presence of a secundum atrial septal defect. Notable at birth was truncal hypotonia with hypertonia of the extremities.

She was referred to genetics for a history of delays and failure to thrive following multiple hospital admissions with negative metabolic workup. Her available growth parameter Z-scores at her most recent visit included height -3.24 and weight -7.99 . She continues to have significant truncal hypotonia at 13 months of age. At the age of 13 months, she is able to roll over, but is unable to crawl or reach a quadruped position. She is nonverbal with concerns for cognitive delays. During her exam, she was noted to have a prominent forehead with bitemporal narrowing, broad nasal bridge, triangular face, pointed chin, deep-set eyes, retrognathia, sparse hair, and two hair whorls (Figure 2f-g). Other physical findings included prominent mammary gland tissue and a sacral pit.

\subsection{Patient 8}

Patient 8 is a 17-year-old female who presented with developmental delays. She was born at term without significant complications during pregnancy or delivery. No significant concerns were noted in the neonatal period.

Her initial genetics evaluation was due to her history of developmental delays. She remains nonverbal but is capable of using limited sign language and communication devices. Her motor milestones have also had significant delays. Additionally, she has stereotypies and other signs concerning for autism although no formal diagnosis has been made. On exam, she had generalized hypotonia and a triangular face with mild retrognathia. Her face was slightly asymmetric with the right side being more prominent than the left. Bilateral exotropia was noted. Ear canals were narrowed. Her feet demonstrated pes planus with broad halluces and scooped toenails. She had right-sided scoliosis with lumbar lordosis. The patient had diffuse hypotonia. Other findings included a brain MRI showing mild cortical volume loss obtained due to papilledema, and renal ultrasound indicating renal cysts and nephrocalcinosis.

\subsection{Patient 9}

Patient 9 is a 4-year and 10-month old female evaluated for a history of global developmental delays. Prenatally, she was noted to have hypoplastic nasal bones, IUGR, and suspected heart failure. The pregnancy and delivery were otherwise uncomplicated.

She was referred at the age of 4 years and 10 months for a genetic evaluation due to her developmental delays and congenital anomalies. She has significant delays in all areas, especially speech.
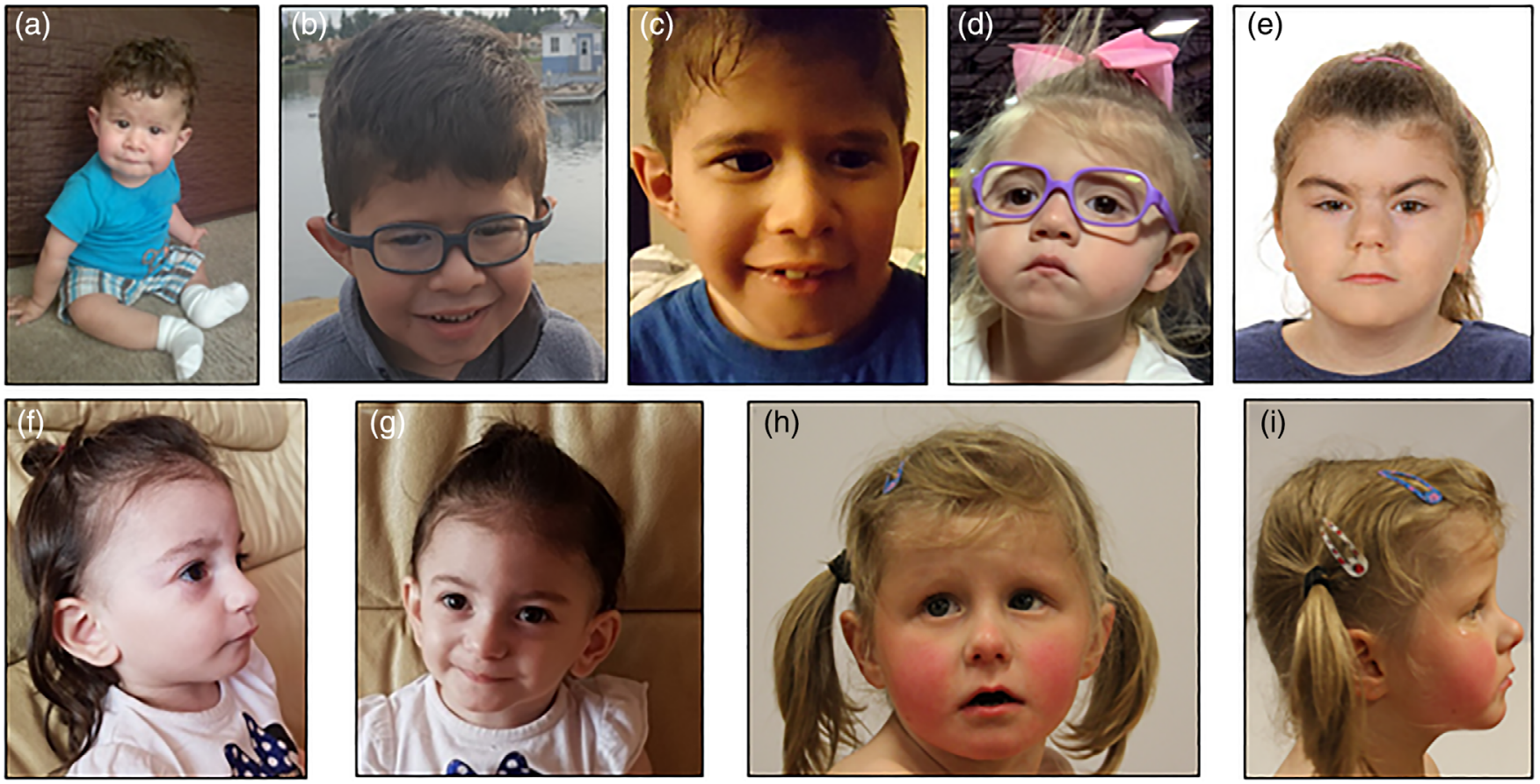

FI G URE 2 (a) Patient 2 at less than 1 year of age. Mild protrusion of upper lip is noted, which is present at subsequent ages. (b) Patient 2 at the age of 3. (c) Patient 2 at the age of 6. (d) Patient 4 at the age of 3. Facial features noted on exam include the bilateral low set ears and downturned corners of the mouth. (e) Patient 5 is noted to share facial features with Cornelia de Lange syndrome including the bushy eyebrows, synophrys, broad nasal tip, long philtrum, thin lips, down-turned mouth corners, and low set ears. (f) Lateral view of Patient 7 at the age of 2 years and 6 months is notable for retrognathia. (g) Anterior view of Patient 7 at the age of 2 years and 6 months is notable for a triangular-shaped face and prominent forehead with bitemporal narrowing. (h) Patient 9 at the age of 9 years and 4 months. Facial features include deep set eyes with bilateral epicanthal folds, short nose with flat nasal bridge, prominent forehead, and a thin upper lip. I) Lateral view of Patient 9 at the age of 9 years and 4 months [Color figure can be viewed at wileyonlinelibrary.com] 
She is nonverbal with concerns for receptive delays. Developmental testing also indicated intellectual disability and autism spectrum disorder. There was a history of febrile seizures at 1 year of age with normal brain MRI and follow-up EEG. At the time of her evaluation, growth parameter Z-scores were height -2.34 , weight -3.78 , and head circumference -2.14 . On exam, she was noted to have a prominent forehead with full cheeks, thin upper lip with downturned corners of the mouth, deep-set eyes, epicanthal folds, a short nose, and central hypotonia (Figure $2 \mathrm{~h}-\mathrm{i}$ ).

\section{I SUMMARY OF IDENTIFIED DDX23 VARIANTS}

The individuals in our cohort all had whole exome sequencing or whole genome sequencing following the completion of the previous genetic testing. Previous testing for each patient is available in Table 1. Of note, chromosomal abnormalities were not ruled out for Patients 3, 5, and 8 prior to whole exome or genome sequencing being ordered. Testing identified de novo missense alterations in DDX23 in all patients (Table 1). Patients 4 and 6 have variants in the same location, which may represent a mutational hotspot within this gene. All variants identified were within the $\mathrm{N}$ - or $\mathrm{C}$-terminal RecAlike domains. Additionally, six of the nine variants are located in conserved motifs involved in ATP-binding and hydrolysis or RNA binding (Möhlmann et al., 2014) (Figure 1).

\section{5 | DISCUSSION}

Herein, we present nine patients with global developmental delay and frequent muscle tone abnormalities with rare de novo alterations in DDX23. All identified variants represent de novo missense changes identified through whole exome or genome sequencing. The DDX23 gene encodes a ubiquitously expressed, highly conserved RNA helicase with multiple roles in the processing and sensing of RNA. The phenotypic similarities of this cohort allow us to propose DDX23 as a gene associated with autosomal dominant syndromic neurodevelopmental delay. The most commonly identified clinical features include tone abnormalities, developmental delays, and a wide spectrum of dysmorphic features.

Clinical features varied among patients. However, all the patients within our cohort (nine of nine patients) presented with global developmental delays, tone abnormalities, and dysmorphic facial features of some kind (Table 2). In particular, speech delay was prominent with five of nine patients being nonverbal. Hypotonia was the most common tone abnormality but two of nine patients presented with either global hypertonia or hypertonia in specific extremities. Other findings seen in more than half of our cohort include seizures, autism spectrum disorder or autistic-like features, short stature, and low weight (Table 2). Among our patients, seizures of varying types (with and without fevers, focal or generalized) were reported in five of the nine patients. Of note, tone abnormalities and autism spectrum disorder have been described in conditions caused by other members of the DDX/DHX RNA helicase gene family, DDX3X and DDX6 (Balak et al., 2019; Snijders Blok et al., 2015). DDX3X is the most welldescribed gene within this protein family with over 150 patients reported in the literature (Snijders Blok et al., 2015).

Although each patient presented with at least one atypical facial feature, physical exam findings were not consistent enough to make the diagnosis easily recognizable in a clinical setting. The most consistent facial features were bitemporal narrowing, prominent forehead, and downturned corners of the mouth. Downturned corners of the mouth may be related to hypotonia in many of the patients, although Patient 5 was noted to have downturned corners of the mouth with a history of hypertonia. Based on this cohort and previously described variants in this protein family, any patient with global developmental delays in the setting of tone abnormalities and mild dysmorphic features should be suspected of having alterations in DDX23 and related genes. Similar features with the addition of movement or gait abnormalities should raise suspicion for alternations in other genes within this family including $D D X 3 X, D H X 30$, and DDX6 (Balak et al., 2019; Lessel et al., 2017; Snijders Blok et al., 2015).

In addition to the wide range of features seen in our patients, several of our patients had phenotypes overlapping recognizable syndromes, such as Cornelia de Lange syndrome (CdLS), Russell-Silver syndrome (RSS), or Prader-Willi syndrome (PWS). Patient 5 has a clinical exam consistent with CdLS with a negative genetic workup for cohesinopathies. At this time, we do not know of any specific connection between the cohesinopathies and DDX23 or other DDX-related genes. It is possible Patient 5 may have a form of CdLS without a recognized gene alteration. A study in 2013 suggests that approximately 16 percent of individuals with clinical signs of CdLS may not have recognizable molecular variants even with testing for mosaicism for the condition (Huisman et al., 2013). Similarly, Patient 6 has some features consistent with CdLS such as an upper extremity anomaly, cleft palate, short stature, and atypical facial features. Two other patients presented with signs and symptoms suggestive of Russell-Silver syndrome (RSS) or Prader-Willi syndrome (PWS). Both patients had negative testing for these two syndromes. In terms of PWS, genetic testing is capable of identifying nearly $100 \%$ of all cases. However, up to $40 \%$ of individuals meeting diagnostic criteria for RSS do not have an identifiable genetic cause (Wakeling et al., 2017). Therefore, although our cohort has phenotypic similarities supportive of a DDX23-related disorder, it is possible that some of our patients have separately identified syndromes with unrecognized molecular diagnoses. Additionally, it is possible that the identified variants in DDX23 are not causative of a phenotype in some or all of the individuals in our cohort.

All of the alterations in the DDX23 gene identified in our cohort were located within the RecA functional domain. The overall structure of the DDX/DHX RNA helicases involves a helicase core consisting of two RecA-like domains connected by a binding domain that acts as the ATP-binding site when in the active conformation (Linder \& Jankowsky, 2011). These domains play an integral role in the processes of transcription, translation, processing, and transportation of 


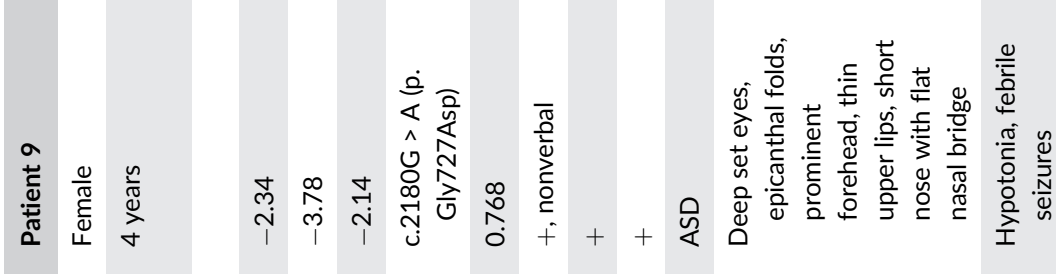

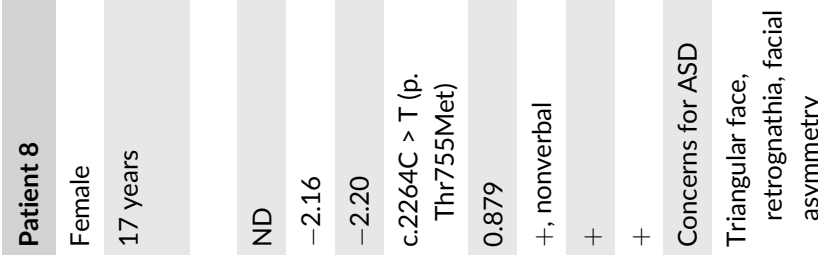
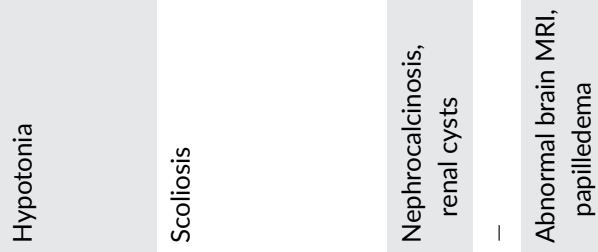

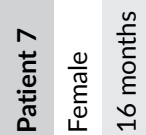

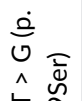

䇉

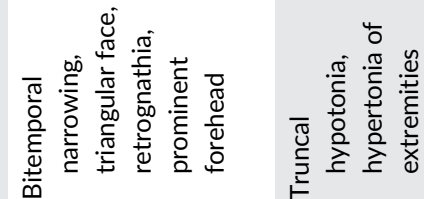

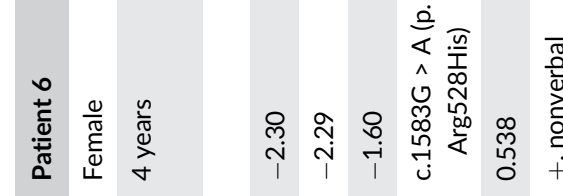

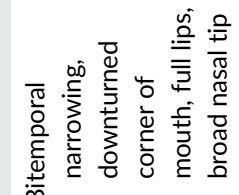

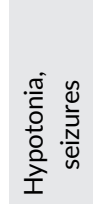

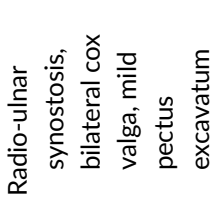

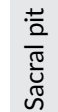

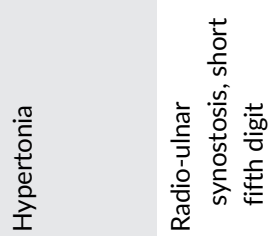

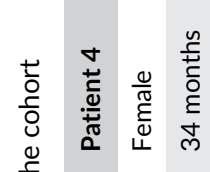
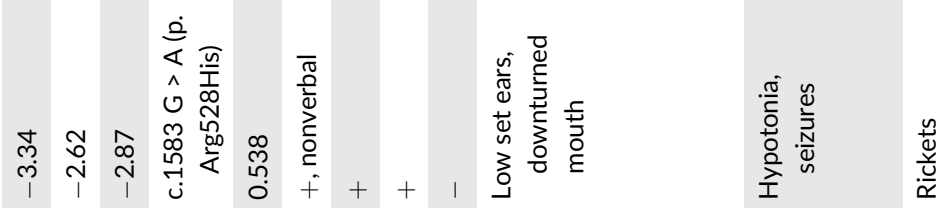

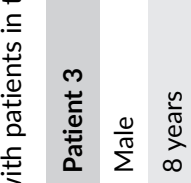

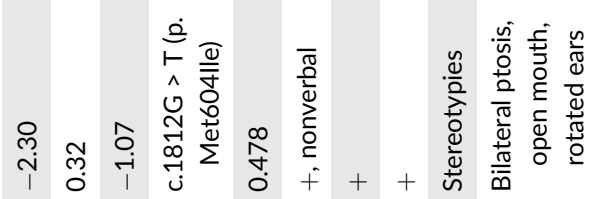

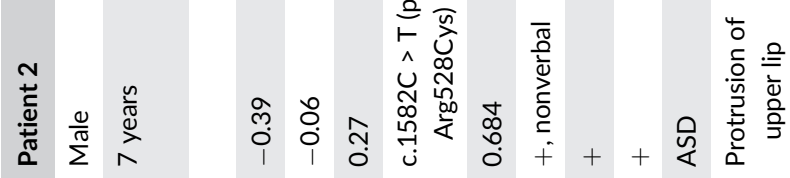

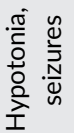

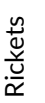

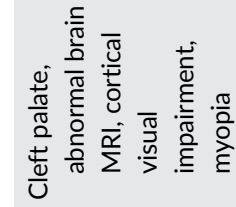

$$
\text { 焉 }
$$

过

ัั.

$\stackrel{0}{\stackrel{0}{2}}$
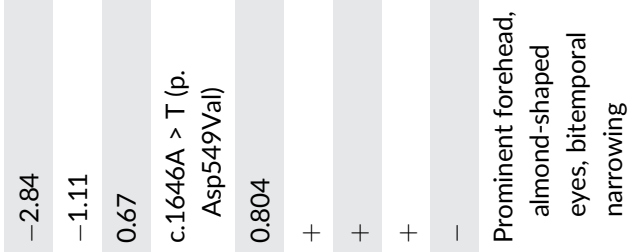

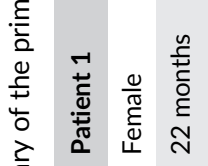

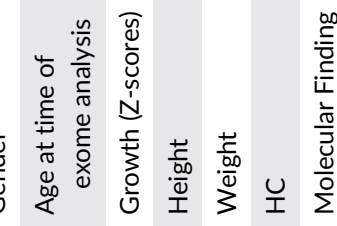

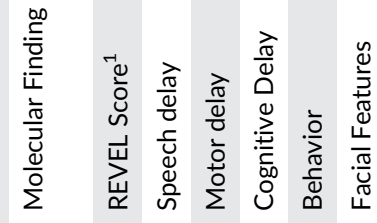
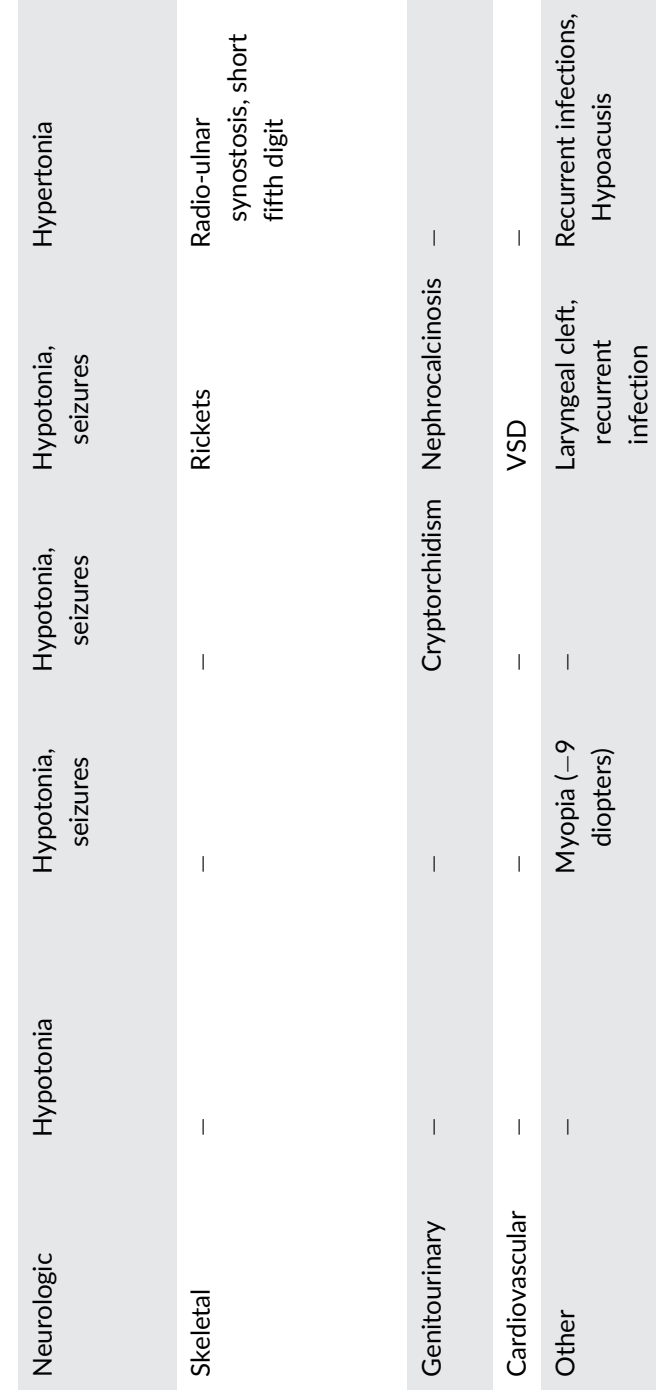


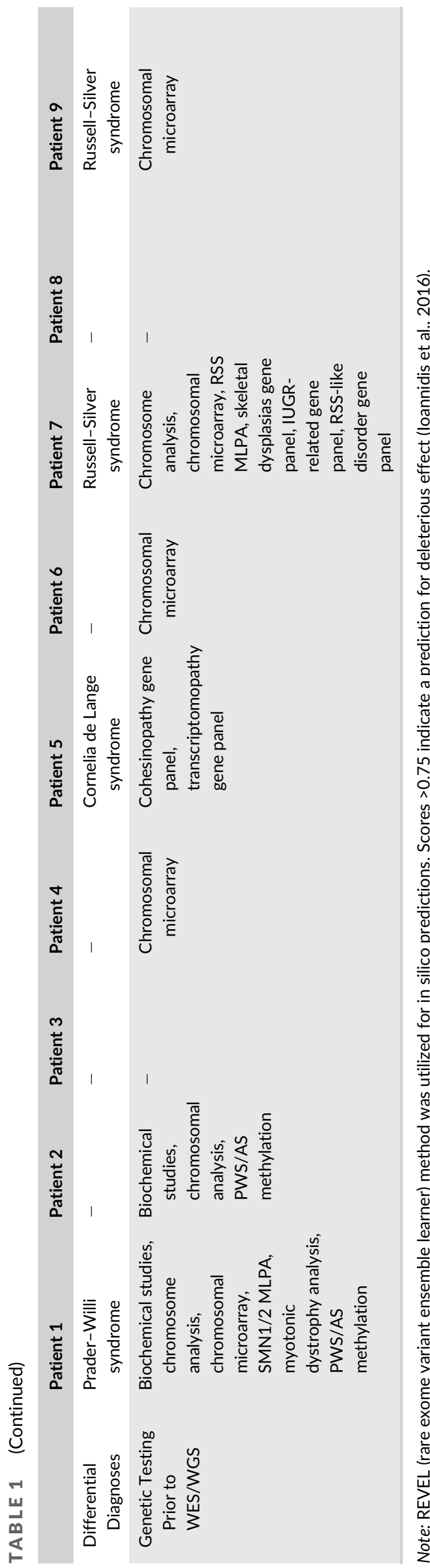

TABLE 2 Summary of total number of patients within cohort with specific clinical features

\begin{tabular}{|l|l|}
\hline Clinical feature & $\begin{array}{l}\text { Total number of } \\
\text { affected patients }\end{array}$ \\
\hline Global developmental delays & $9 / 9(100 \%)$ \\
\hline Tone abnormalities & $9 / 9(100 \%)$ \\
\hline Dysmorphic facial features & $9 / 9(100 \%)$ \\
\hline Short stature & $6 / 9(66.7 \%)$ \\
\hline Autism or Autistic-like features & $5 / 9(55.6 \%)$ \\
\hline Seizures & $5 / 9(55.6 \%)$ \\
\hline Low weight & $5 / 9(55.6 \%)$ \\
\hline Microcephaly & $4 / 9(44.4 \%)$ \\
\hline Skeletal anomalies & $4 / 9(44.4 \%)$ \\
\hline Genitourinary abnormalities & $3 / 9(33.3 \%)$ \\
\hline Vision abnormalities & $2 / 9(22.2 \%)$ \\
\hline Cardiac anomalies & $1 / 9(11.1 \%)$ \\
\hline
\end{tabular}

RNA in the cell (Bleichert \& Baserga, 2007; Bourgeois et al., 2016; Linder \& Jankowsky, 2011; Putnam \& Jankowsky, 2013). These are highly conserved domains among the proteins in the family with several conserved motifs involved in ATP-binding and hydrolysis and RNA binding. Interestingly, Patients 1, 8, and 9 had variants located in conserved ATP-binding and hydrolysis motifs, which may alter enzyme kinetics. Additionally, codon 528 is involved in RNA binding within the $\mathrm{N}$-terminal RecA-like domain, and de novo alterations of this position were identified in three out of the nine patients in this study, which suggests that this may be a mutational hot spot.

$D D X 23$ gene constraint analyses indicate that missense alterations are not tolerated ( $Z$ score $=4.62$ ), whereas loss of function alterations are tolerated ( $\mathrm{pLI}$ score $=0.54$ and observed/expected score $=0.22$ ) (Lek et al., 2016). These findings suggest that the molecular mechanism of pathogenesis is not likely to be through haploinsufficiency, but rather via gain of function or dominant negative action. In silico prediction models indicate a deleterious effect is expected in at least three of the identified alterations (Patients 1, 8, and 9). Other variant in silico prediction scores indicate a moderate chance these alterations are deleterious to protein function (loannidis et al., 2016). Additionally, the location of the variants does not appear to correlate to the severity of neurodevelopmental delays or other symptoms in our patient cohort. Thus, no genotype-phenotype correlation can be made based on this study. Further studies are required to fully elucidate the mechanism of disease and additional patients are needed to determine if there is a genotype-phenotype correlation including functional characterization of the gene and these variants as well as protein modeling.

The DHX/DDX family of proteins have been increasingly associated with human disorders, particularly neurodevelopmental disorders. The name originates from a highly conserved amino acid sequence of D-E-A-D/H (Asp-Glu-Ala-Asp/His) in the Walker B motif (motif II) of the RecA-1 domain shared by members of the protein family. With the first protein being initially described in the 1980 s, the 
DDX/DHX RNA helicases now compose a large superfamily of over 50 proteins (Linder \& Fuller-Pace, 2013). A brief literature review identified at least 13 separate helicase genes correlated with clinical phenotypes (Ajmal et al., 2014; Balak et al., 2019; Favaro et al., 2014; Jang et al., 2015; Latif Z et al., 2018; Lessel et al., 2017; Paine et al., 2019; Polprasert et al., 2015; van der Lelij et al., 2010). The clinical features of the individuals in our cohort fit well with the previously identified neurodevelopmental disorders noted in this family of proteins. The most common recognizable syndrome associated with DEAD/H box RNA helicases with a neurodevelopmental phenotype is the $D D X 3 X$-related intellectual disability. It is estimated to cause up to $0.5 \%$ of developmental delay overall and $2 \%$ of developmental delay in females (Wang et al., 2018). DHX30 and DDX6 cause global developmental delays with gait abnormalities and more consistent facial dysmorphism (Balak et al., 2019; Lessel et al., 2017). Depending on the specific helicase and the tissue expression, the phenotypes can also include gonadal dysgenesis ( $D H X 37$ ), early onset retinitis pigmentosa (DHX38), and syndromes of congenital anomalies, such as Richieri-Costa-Pereira syndrome (EIF4A3). The degree of variability between the specific family members of this highly conserved protein family may be secondary to the differential tissue expression, variations in the $\mathrm{C}$ - and $\mathrm{N}$-terminal domains, or combinations of factors.

Given the increasing relationship between $\mathrm{DEAD} / \mathrm{H}$ box RNA helicase alterations and human disease, further functional studies wil be important to clarify disease mechanisms and expand our knowledge of this growing set of related disorders. Given the breadth of the defined and proposed functions of DDX23, future efforts will be aimed at characterizing the impact of these variants on DDX23's roles in RNA processing, the maintenance of genome stability, and its ability to act as a sensor for dsRNA. This last function could be relevant in the defense against viruses that carry their genetic information as dsRNA. Defining the contribution of these different functions to each associated phenotype is likely to uncover pathogenic mechanisms that are shared with other DEAD/H box RNA helicases, as well as those that are unique to $D D \times 23$.

\section{6 | CONCLUSION}

We propose that this cohort adds DDX23 to the expanding set of DDX/DHX-related disorders, but this requires confirmation with functional validation and additional reported cases. Patients with alterations in DDX23 also appear to have an increased risk for autism spectrum disorder, seizures, and atypical facial features. Functional studies are needed to further elucidate the underlying mechanism causing these features. Based on gene constraint metrics and the location of missense alterations described herein, dominant negative or gain of function, rather than loss of function, appears to be the most likely mechanism. For patients with neurodevelopmental symptoms, variants discovered in DDX23 should be considered as possible causes. Our cohort adds DDX23 to the emerging number of DEAD/H box RNA helicase related disorders.

\section{ACKNOWLEDGMENTS}

We thank the patients and their families for participating in this study. Isabelle Thiffault's work is supported by generous donors to the Children's Mercy Research Institute and the Genomic Answers for Kids program.

\section{CONFLICT OF INTEREST}

Dr. Raymond J. Louie is a clinical laboratory director in molecular genetics and the Greenwood Genetic Center receives fee income from clinical laboratory testing. The GeneDx authors are employees of GeneDx, Inc. Dr. Heather M. McLaughlin is an employee and stakeholder at Invitae Corporation. Otherwise the authors report no conflicts of interest.

\section{AUTHOR CONTRIBUTIONS}

Conceptualization and design: William Burns, Rich Steet, Michael J. Lyons., Raymond J. Louie; Data acquisition and interpretation: Raymond J. Louie, Lynne M. Bird, Divya Ramanchandra, Isabelle Thiffault, Ilaria Parenti, Korbinian M. Riedhammer, Neda Zadeh, Joseph Porrman; Manuscript draft: William Burns, Rich Steet, Michael J. Lyons., Raymond J. Louie; Manuscript revision: William Burns, Rich Steet, Michael J. Lyons., Raymond J. Louie, Lynne M. Bird, Delphine Heron, Boris Keren, Divya Ramanchandra, Heather M. McLaughlin, Korbinian M. Reidhammer, Isabelle Thiffault, Frank J. Kaiser, Jolanta Wierzba, Susanne Liptay, Neda Zadeh, Joseph Porrman, Andrea Fischer, Sophie Gößwein, Heather M. McLaughlin, Aida Telegrafi, Katherine G. Langley.

\section{DATA AVAILABILITY STATEMENT}

All variants described in this study have been or will be deposited in ClinVar; accession numbers pending (Accession numbers: SCV001439281.1 and SCV001234603.1). Variant c.1625G>A (p.Arg542His) is pending submission.

\section{ORCID}

William Burns (D) https://orcid.org/0000-0002-3957-5720 Isabelle Thiffault (D) https://orcid.org/0000-0001-7987-6731 Korbinian M. Riedhammer (D) https://orcid.org/0000-0002-7503-5801 Raymond J. Louie (D) https://orcid.org/0000-0002-6788-1151

\section{REFERENCES}

Ajmal, M., Khan, M. I., Neveling, K., Khan, Y. M., Azam, M., Waheed, N. K., Hamel, C. P., Ben-Yosef, T., De Baere, E., Koenekoop, R. K., Collin, R. W., Qamar, R., \& Cremers, F. P. (2014). A missense mutation in the splicing factor gene DHX38 is associated with early-onset retinitis pigmentosa with macular coloboma. Journal of Medical Genetics, 51 (7), 444-448. https://doi.org/10.1136/jmedgenet-2014-102316

Balak, C., Benard, M., Schaefer, E., Iqbal, S., Ramsey, K., Ernoult-Lange, M., Mattioli, F., Llaci, L., Geoffroy, V., Courel, M., Naymik, M., Bachman, K. K., Pfundt, R., Rump, P., Ter Beest, J., Wentzensen, I. M., Monaghan, K. G., McWalter, K., Richholt, R., ... Piton, A. (2019). Rare de novo missense variants in RNA helicase DDX6 cause intellectual disability and dysmorphic features and Lead to P-body defects and RNA dysregulation. American Journal of Human Genetics, 105(3), 509525. https://doi.org/10.1016/j.ajhg.2019.07.010 
Bleichert, F., \& Baserga, S. J. (2007). The long unwinding road of RNA helicases. Molecular Cell, 27(3), 339-352. https://doi.org/10.1016/j. molcel.2007.07.014

Bourgeois, C. F., Mortreux, F., \& Auboeuf, D. (2016). The multiple functions of RNA helicases as drivers and regulators of gene expression. Nature Reviews, 17(7), 426-438. https://doi.org/10.1038/nrm. 2016.50

Chae, Y. K., Chung, S. Y., Davis, A. A., Carneiro, B. A., Chandra, S., Kaplan, J., Kalyan, A., \& Giles, F. J. (2015). Adenoid cystic carcinoma: Current therapy and potential therapeutic advances based on genomic profiling. Oncotarget, 6(35), 37117-37134. https://doi.org/10.18632/ oncotarget.5076

Favaro, F. P., Alvizi, L., Zechi-Ceide, R. M., Bertola, D., Felix, T. M., de Souza, J., Raskin, S., Twigg, S. R., Weiner, A. M., Armas, P., Margarit, E., Calcaterra, N. B., Andersen, G. R., McGowan, S. J., Wilkie, A. O., Richieri-Costa, A., de Almeida, M. L., \& Passos-Bueno, M. R. (2014). A noncoding expansion in EIF4A3 causes Richieri-Costa-Pereira syndrome, a craniofacial disorder associated with limb defects. American Journal of Human Genetics, 94(1), 120-128. https://doi.org/10.1016/j. ajhg.2013.11.020

Huisman, S. A., Redeker, E. J., Maas, S. M., Mannens, M. M., \& Hennekam, R. C. (2013). High rate of mosaicism in individuals with Cornelia de Lange syndrome. Journal of Medical Genetics, 50(5), 339344. https://doi.org/10.1136/jmedgenet-2012-101477

Ioannidis, N. M., Rothstein, J. H., Pejaver, V., Middha, S., McDonnell, S. K., Baheti, S., Musolf, A., Li, Q., Holzinger, E., Karyadi, D., CannonAlbright, L. A., Teerlink, C. C., Stanford, J. L., Isaacs, W. B., Xu, J., Cooney, K. A., Lange, E. M., Schleutker, J., Carpten, J. D., ... Sieh, W. (2016). REVEL: An ensemble method for predicting the pathogenicity of rare missense variants. American Journal of Human Genetics, 99(4), 877-885. https://doi.org/10.1016/j.ajhg.2016.08.016

Jang, M. A., Kim, E. K., Now, H., Nguyen, N. T., Kim, W. J., Yoo, J. Y., Lee, J., Jeong, Y. M., Kim, C. H., Kim, O. H., Sohn, S., Nam, S. H., Hong, Y., Lee, Y. S., Chang, S. A., Jang, S. Y., Kim, J. W., Lee, M. S., Lim, S. Y., ... Ki, C. S. (2015). Mutations in DDX58, which encodes RIG-I, cause atypical singleton-Merten syndrome. American Journal of Human Genetics, 96(2), 266-274. https://doi.org/10.1016/j.ajhg.2014. 11.019

Latif, Z., Chakchouk, I., Schrauwen, I., Lee, K., Santos-Cortez, R., Abbe, I., Acharya, A., Jarral, A., Ali, I., Ullah, E., Khan, M. N., Ali, G., Tahir, T. H., Bamshad, M. J., Nickerson, D. A., Ahmad, W., Ansar, M., Leal, S. M., \& University of Washington Center for Mendelian Genomics (UWCMG) Study Group. (2018). Confirmation of the role of DHX38 in the etiology of early-onset retinitis Pigmentosa. Investigative Ophthalmology \& Visual Science, 59(11), 4552-4557. https://doi.org/10.1167/iovs.1823849

Lek, M., Karczewski, K. J., Minikel, E. V., Samocha, K. E., Banks, E., Fennell, T., O'Donnell-Luria, A. H., Ware, J. S., Hill, A. J., Cummings, B. B., Tukiainen, T., Birnbaum, D. P., Kosmicki, J. A., Duncan, L. E., Estrada, K., Zhao, F., Zou, J., Pierce-Hoffman, E., Berghout, J., ... Exome Aggregation Consortium. (2016). Analysis of protein-coding genetic variation in 60,706 humans. Nature, 536(7616), 285-291. https://doi.org/10.1038/nature19057

Lessel, D., Schob, C., Küry, S., Reijnders, M., Harel, T., Eldomery, M. K., Coban-Akdemir, Z., Denecke, J., Edvardson, S., Colin, E., Stegmann, A., Gerkes, E. H., Tessarech, M., Bonneau, D., Barth, M., Besnard, T., Cogné, B., Revah-Politi, A., Strom, T. M., ... Kreienkamp, H. J. (2017). De novo missense mutations in DHX30 impair global translation and cause a neurodevelopmental disorder. American Journal of Human Genetics, 101(5), 716-724. https://doi.org/10.1016/j.ajhg.2017. 09.014

Linder, P., \& Fuller-Pace, F. V. (2013). Looking back on the birth of DEADbox RNA helicases. Biochimica et Biophysica Acta, 1829(8), 750-755. https://doi.org/10.1016/j.bbagrm.2013.03.007
Linder, P., \& Jankowsky, E. (2011). From unwinding to clamping-the DEAD box RNA helicase family. Nature Reviews, 12(8), 505-516. https://doi.org/10.1038/nrm3154

Mao, G., Jin, H., \& Wu, L. (2017). DDX23-Linc00630-HDAC1 axis activates the notch pathway to promote metastasis. Oncotarget, 8(24), 38937-38949. https://doi.org/10.18632/oncotarget.17156

Möhlmann, S., Mathew, R., Neumann, P., Schmitt, A., Lührmann, R., \& Ficner, R. (2014). Structural and functional analysis of the human spliceosomal DEAD-box helicase Prp28. Acta Crystallographica, 70(Pt 6), 1622-1630. https://doi.org/10.1107/S1399004714006439

Paine, I., Posey, J. E., Grochowski, C. M., Jhangiani, S. N., Rosenheck, S., Kleyner, R., Marmorale, T., Yoon, M., Wang, K., Robison, R., Cappuccio, G., Pinelli, M., Magli, A., Coban Akdemir, Z., Hui, J., Yeung, W. L., Wong, B., Ortega, L., Bekheirnia, M. R., ... Lupski, J. R. (2019). Paralog studies augment gene discovery: DDX and DHX genes. American Journal of Human Genetics, 105(2), 302-316. https://doi.org/ 10.1016/j.ajhg.2019.06.001

Polprasert, C., Schulze, I., Sekeres, M. A., Makishima, H., Przychodzen, B., Hosono, N., Singh, J., Padgett, R. A., Gu, X., Phillips, J. G., Clemente, M., Parker, Y., Lindner, D., Dienes, B., Jankowsky, E., Saunthararajah, Y., Du, Y., Oakley, K., Nguyen, N., ... Maciejewski, J. P. (2015). Inherited and somatic defects in DDX41 in myeloid neoplasms. Cancer Cell, 27(5), 658-670. https://doi.org/10.1016/j.ccell.2015. 03.017

Putnam, A. A., \& Jankowsky, E. (2013). DEAD-box helicases as integrators of RNA, nucleotide and protein binding. Biochimica et Biophysica Acta, 1829(8), 884-893. https://doi.org/10.1016/j.bbagrm.2013.02.002

Ruan, J., Cao, Y., Ling, T., Li, P., Wu, S., Peng, D., Wang, Y., Jia, X., Chen, S., Xu, A., \& Yuan, S. (2019). DDX23, an evolutionary conserved dsRNA sensor, participates in innate antiviral responses by pairing with TRIF or MAVS. Frontiers in Immunology, 10, 2202. https://doi.org/10.3389/ fimmu.2019.02202

Snijders Blok, L., Madsen, E., Juusola, J., Gilissen, C., Baralle, D., Reijnders, M. R., Venselaar, H., Helsmoortel, C., Cho, M. T., Hoischen, A., Vissers, L. E., Koemans, T. S., Wissink-Lindhout, W., Eichler, E. E., Romano, C., Van Esch, H., Stumpel, C., Vreeburg, M., Smeets, E., ... Kleefstra, T. (2015). Mutations in DDX3X are a common cause of unexplained intellectual disability with gender-specific effects on Wnt signaling. American Journal of Human Genetics, 97(2), 343352. https://doi.org/10.1016/j.ajhg.2015.07.004

Sobreira, N., Schiettecatte, F., Valle, D., \& Hamosh, A. (2015). GeneMatcher: A matching tool for connecting investigators with an interest in the same gene. Human Mutation, 36(10), 928-930. https:// doi.org/10.1002/humu.22844

Sridhara, S. C., Carvalho, S., Grosso, A. R., Gallego-Paez, L. M., CarmoFonseca, M., \& de Almeida, S. F. (2017). Transcription dynamics prevent RNA-mediated genomic instability through SRPK2-dependent DDX23 phosphorylation. Cell Reports, 18(2), 334-343. https://doi.org/ 10.1016/j.celrep.2016.12.050

Teigelkamp, S., Mundt, C., Achsel, T., Will, C. L., \& Lührmann, R. (1997). The human U5 snRNP-specific $100-k D$ protein is an RS domain-containing, putative RNA helicase with significant homology to the yeast splicing factor Prp28p. RNA (New York, N.Y.), 3(11), 1313-1326.

van der Lelij, P., Chrzanowska, K. H., Godthelp, B. C., Rooimans, M. A., Oostra, A. B., Stumm, M., Zdzienicka, M. Z., Joenje, H., \& de Winter, J. P. (2010). Warsaw breakage syndrome, a cohesinopathy associated with mutations in the XPD helicase family member DDX11/ChIR1. American Journal of Human Genetics, 86(2), 262-266. https://doi.org/10.1016/j.ajhg.2010.01.008

Wakeling, E. L., Brioude, F., Lokulo-Sodipe, O., O'Connell, S. M., Salem, J., Bliek, J., Canton, A. P., Chrzanowska, K. H., Davies, J. H., Dias, R. P., Dubern, B., Elbracht, M., Giabicani, E., Grimberg, A., Grønskov, K., Hokken-Koelega, A. C., Jorge, A. A., Kagami, M., Linglart, A., ... Netchine, I. (2017). Diagnosis and management of silver-Russell 
syndrome: First international consensus statement. Nature Reviews. Endocrinology, 13(2), 105-124. https://doi.org/10.1038/nrendo. 2016.138

Wang, X., Posey, J. E., Rosenfeld, J. A., Bacino, C. A., Scaglia, F., Immken, L., Harris, J. M., Hickey, S. E., Mosher, T. M., Slavotinek, A., Zhang, J., Beuten, J., Leduc, M. S., He, W., Vetrini, F., Walkiewicz, M. A., Bi, W., Xiao, R., Liu, P., ... Moretti, P. (2018). Phenotypic expansion in $D D X 3 X$ - a common cause of intellectual disability in females. Annals of Clinical and Translational Neurology, 5(10), 12771285. https://doi.org/10.1002/acn3.622

Yin, J., Park, G., Lee, J. E., Choi, E. Y., Park, J. Y., Kim, T. H., Park, N., Jin, X., Jung, J. E., Shin, D., Hong, J. H., Kim, H., Yoo, H., Lee, S. H., Kim, Y. J., Park, J. B., \& Kim, J. H. (2015). DEAD-box RNA helicase DDX23 modulates glioma malignancy via elevating miR-21 biogenesis. Brain: $\mathrm{A}$ Journal of Neurology, 138(Pt 9), 2553-2570. https://doi.org/10.1093/ brain/awv167

How to cite this article: Burns, W., Bird, L. M., Heron, D., Keren, B., Ramachandra, D., Thiffault, I....Lyons, M. J. (2021). Syndromic neurodevelopmental disorder associated with de novo variants in DDX23. American Journal of Medical Genetics Part A Part A, 1-10. https://doi.org/10.1002/ajmg.a.62359 